\title{
Influência da forma física da ração e da linhagem sobre o desempenho e rendimento de cortes de frangos de corte
}

[Influence of physical form of ration and lineage on the performance and yield of broiler cuts]

\author{
L.J.C. Lara ${ }^{1}$, N.C. Baião ${ }^{1}$, J.S.R. Rocha ${ }^{2}$, A.M.Q. Lana ${ }^{1}$, S.V. Cançado ${ }^{1}$, D.O. Fontes ${ }^{1}$, R.S. Leite ${ }^{2}$ \\ ${ }^{1}$ Escola de Veterinária - UFMG \\ Caixa Postal 567 \\ 30123-970 - Belo Horizonte, MG \\ ${ }^{2}$ Aluno de pós-graduação - EV-UFMG - Belo Horizonte, MG
}

\section{RESUMO}

Avaliou-se o efeito da forma física da ração sobre o desempenho e o rendimento de cortes de duas linhagens de frangos de corte, Cobb e Ross. Foram utilizados 900 frangos machos, criados em galpão experimental, com idades entre um a 45 dias. Os tratamentos foram definidos pela linhagem e forma física da ração da seguinte forma: (T1) ração farelada à vontade, (T2) ração peletizada à vontade e (T3) ração peletizada controlada. Para avaliação do desempenho, o delineamento experimental foi 0 inteiramente ao acaso, em arranjo fatorial 3 x 2 (três dietas e duas linhagens) e cinco repetições, sendo cada repetição composta de 30 aves. Para a avaliação do rendimento de cortes da carcaça, o delineamento foi o mesmo, com exceção do número de repetições, que foi de 30 , sendo cada ave considerada como uma repetição. A ração peletizada controlada reduziu o ganho de peso em relação à peletizada à vontade em $4,7 \%$ e melhorou a viabilidade da linhagem Cobb em 10\%. Independentemente da linhagem, maiores ganhos de peso foram obtidos quando as aves foram alimentadas com ração peletizada à vontade. A restrição alimentar favoreceu a conversão alimentar das aves em $2 \%$. A linhagem não influenciou os parâmetros de rendimento de cortes e porcentagens de órgãos digestivos avaliados. A peletização favorece o desempenho de frangos de corte.

Palavras- chave: frango de corte, linhagem, peletização, desempenho, rendimento de cortes

\begin{abstract}
The effect of physical form of the rations on the performance and yield of cuts of the carcass of two lineages of broilers (Cobb and Ross) was evaluated. The treatments were defined according to the lineages and physical form of the rations and were given mash ad libitum, pelleted ad libitum, and restricted pelleted (with equal intake of the given mash ration). In the trial, 900-day-old broilers were raised in experimental poultry house from 1 to 45 days of age. To evaluate the performance, the statistical design was the complete randomized with $3 \times 2$ (three diets and two lines) factorial arrangement with five repetitions, being 30 birds in each repetition. To evaluate the carcass and yield of cuts, the statistical design was the same, with 30 birds for each treatment, being each bird considered one repetition. The restricted pelleted ration reduced the weight of gain in $4.7 \%$ and enhanced the viability of the lineage Cobb in 10\%. Independently of the lineage, better weight of gain were observed in birds fed pelleted rations ad libitum. The restriction of the pelleted ration enhanced the feed conversion in $2 \%$. The lineage did not influence the yield of cuts and percentage of digestive organs evaluated. The pelletization enhances the performance of broilers.
\end{abstract}

Keywords: broiler, live, pelleted, performance, yield of cuts

Recebido em 3 de maio de 2007

Aceito em 12 de maio de 2008

E-mail: leolara@uol.com.br

Apoio: FAPEMIG 


\section{INTRODUÇÃO}

Os benefícios da utilização de rações peletizadas em comparação às rações fareladas no desempenho de frangos de corte são bem definidos em vários trabalhos de pesquisa. Os principais benefícios são o aumento do consumo de ração, a melhora na digestibilidade dos nutrientes, a facilidade de apreensão da ração e o aumento da energia produtiva em função de menor gasto de tempo para consumo (Jensen et al., 1962; Briggs et al.,1999; López e Baião, 2002).

Benett et al. (2002) observaram melhora de desempenho de frangos alimentados com rações peletizadas em comparação com os alimentados com ração farelada. Mas os frangos que receberam as rações peletizadas apresentaram maior mortalidade por síndrome da morte súbita e menor percentagem de moela que aqueles alimentados com rações fareladas. $\mathrm{O}$ rendimento de carcaça e a percentagem de gordura abdominal não foram influenciados pela forma física da ração.

Amornthewaphat et al. (2005) avaliaram o efeito da forma física da ração sobre o desempenho de frangos de corte da linhagem Ross e observaram aumentos de consumo, ganho de peso e mortalidade, além de melhor conversão alimentar para aves alimentadas com rações peletizadas. Os autores sugeriram que os benefícios da peletização podiam ser atribuídos ao menor desperdício, à menor seleção de ingredientes e ao maior consumo de ração.

Segundo Havenstein et al. (2003), de 1957 a 2001, o melhoramento genético foi responsável por $85 \%$ da evolução no desempenho de frangos de corte. Em consequiência disso, trabalhos que avaliem linhagens são muito importantes pelo valor que o melhoramento genético tem no desenvolvimento da avicultura e em função da rapidez com que as mudanças ocorrem nesse segmento da avicultura.

Os frangos de corte das linhagens atuais são caracterizados por altas taxas de crescimento inicial associado com aumento de deposição de gordura e incidências de problemas locomotores e doenças metabólicas. Vários estudos demonstraram que restrições no crescimento de aves, acompanhadas de tempo suficiente para ganho compensatório, podem prevenir os problemas citados, sem diminuição do desempenho, e favorecer a conversão alimentar. No entanto, essa recuperação no desempenho é dependente da severidade da restrição, estádio de desenvolvimento da ave no começo da restrição e período de duração da restrição (Gonzales et al., 1998a; Lippens et al., 2002).

O objetivo deste experimento foi avaliar os efeitos da forma física da ração e da linhagem sobre o desempenho, rendimento de cortes e as porcentagens de coração, intestino, fígado e moela de frangos de corte.

\section{MATERIAL E MÉTODOS}

O experimento foi realizado no período de 28 de janeiro a 13 de março de 2006. As aves, alojadas em galpão experimental convencional, foram submetidas ao manejo semelhante àqueles usados em criações comerciais. Foram utilizados 900 pintos de corte, machos, das linhagens Cobb e Ross, de um dia de idade, alojando-se 30 aves por boxe $\left(12 \mathrm{aves} / \mathrm{m}^{2}\right)$, com água e ração oferecidas à vontade. O período de criação foi de um a 45 dias de idade. Foram utilizados três tipos de rações de acordo com a fase de criação: inicial, de um a 21 dias de idade; crescimento, de 22 a 40 dias de idade; e acabamento, de 41 a 45 dias de idade. A composição das rações, de acordo com as fases, foi exatamente a mesma (Tab. 1), diferindo apenas na forma física. Os níveis nutricionais dos ingredientes foram obtidos das tabelas brasileiras de aves e suínos (Rostagno et al., 2005). Os níveis nutricionais das rações foram considerados de acordo com os normalmente utilizados pelo setor de avicultura da Escola de Veterinária da UFMG (Lara et al., 2005). A fitase utilizada foi adicionada antes da peletização.

Os tratamentos foram constituídos da seguinte forma: duas linhagens (Cobb e Ross), alimentados com ração farelada à vontade, peletizada à vontade e peletizada com consumo restrito, semelhante ao da ração farelada à vontade. 
Tabela 1. Composição percentual e níveis nutricionais calculados das rações utilizadas

\begin{tabular}{|c|c|c|c|}
\hline Ingredientes & Inicial & Crescimento & Acabamento \\
\hline Milho moído & 60,1 & 65,0 & 69,0 \\
\hline Farelo de soja $46 \%$ PB & 25,8 & 10,9 & 6,65 \\
\hline Soja integral tostada & 4,9 & 10,9 & 11,5 \\
\hline Óleo de vísceras & 0,7 & 0,75 & 0,75 \\
\hline F.de carne e ossos $40 \%$ PB & 2,55 & 2,43 & 2,32 \\
\hline Farinha de penas & 1,25 & 4,0 & 3,5 \\
\hline Farinha de vísceras & 3,0 & 4,0 & 4,5 \\
\hline Sal comum & 0,37 & 0,31 & 0,29 \\
\hline DL-Metionina & 0,207 & 0,166 & 0,154 \\
\hline L-Lisina & 0,18 & 0,44 & 0,44 \\
\hline Colina $70 \%$ & 0,066 & 0,055 & 0,04 \\
\hline Sup. vitamínico mineral ${ }^{1,2,3}$ & 0,1 & 0,1 & 0,1 \\
\hline Fitase & 0,015 & 0,015 & 0,015 \\
\hline Enramicina & - & 0,01 & - \\
\hline Avilamicina & 0,0075 & - & - \\
\hline Metil benzoquato/clopidol & 0,05 & - & - \\
\hline Salinomicina & - & 0,055 & - \\
\hline Calcário & 0,7045 & 0,894 & 0,741 \\
\hline Total (\%) & 100,00 & 100,00 & 100,00 \\
\hline Nível nutricional & Inicial & Crescimento & Acabamento \\
\hline Proteína bruta $(\%)$ & 22,5 & 21,0 & 19,5 \\
\hline Energia metab. (kcal/kg) & 3050 & 3210 & 3260 \\
\hline Cálcio $(\%)$ & 0,92 & 0,90 & 0,88 \\
\hline Fósforo disponível (\%) & 0,47 & 0,42 & 0,42 \\
\hline Lisina total $(\%)$ & 1,27 & 1,21 & 1,10 \\
\hline Metionina total $(\%)$ & 0,54 & 0,48 & 0,44 \\
\hline Metionina + cistina $(\%)$ & 0,92 & 0,89 & 0,83 \\
\hline Sódio $(\%)$ & 0,20 & 0,20 & 0,20 \\
\hline \multirow{2}{*}{$\begin{array}{l}\mathrm{PB}=\text { proteína bruta } \\
{ }^{1} \text { Fase inicial: Vit. A } 13.685 \mathrm{UI} \text {, Vit. D3 } 3.157 \mathrm{UI} \text {, Vit. E } \\
35,0 \mathrm{mg} \text {, Vit. K3 4,410mg, Vit. B1 } 2,415 \mathrm{mg} \text {, Vit. B2 } \\
8,662,5 \mathrm{mg} \text {, Vit. B6 5,460mg, Vit. B12 } 21,315 \mathrm{mcg} \text {, Biotina } \\
96,250 \mathrm{mcg} \text {, Niacina } 53,900 \mathrm{mg} \text {, Ac. fólico } 1,228,5 \mathrm{mg} \text {, Ac. } \\
\text { pantotênico 13,860mg, Selênio 0,3mg, Iodo } 1,0 \mathrm{mg} \text {, Ferro } \\
30,0 \mathrm{mg} \text {, Cobre } 10,0 \mathrm{mg} \text {, Manganês } 90,0 \mathrm{mg} \text {, Zinco } 80 \text {,0mg. }\end{array}$} & \multicolumn{3}{|c|}{$\begin{array}{l}\text { 6,187,5mg, Vit. B6 3,900mg, Vit. B12 } 15,225 \mathrm{mcg} \text {, Biotina } \\
68,750 \mathrm{mcg} \text {, Niacina } 38,500 \mathrm{mg} \text {, Ac. fólico 0,87mg, Ac. } \\
\text { pantotênico 9,900mg, Selênio 0,21mg, Iodo } 1,0 \mathrm{mg} \text {, Ferro } \\
\text { 30,0mg, Cobre 10,0mg, Manganês } 90,0 \mathrm{mg} \text {, Zinco } 80,0 \mathrm{mg} \text {. }\end{array}$} \\
\hline & \multirow{2}{*}{\multicolumn{3}{|c|}{$\begin{array}{l}{ }^{3} \text { Fase acabamento: Vit. A } 7.038 \mathrm{UI} \text {, Vit. D3 } 1.584 \mathrm{UI} \text {, Vit. E } \\
18,0 \mathrm{mg} \text {, Vit. K3 2,268mg, Vit. B1 } 1,242 \mathrm{mg} \text {, Vit. B2 } \\
4,445 \mathrm{mg} \text {, Vit. B6 2,808mg, Vit. B12 } 10,962 \mathrm{mcg} \text {, Biotina } \\
49,500 \mathrm{mcg} \text {, Niacina } 27,720 \mathrm{mg} \text {, Ac. fólico } 0,632 \mathrm{mg} \text {, Ac. } \\
\text { pantotênico } 7,128 \mathrm{mg} \text {, Selênio 0,15mg, Iodo } 1,0 \mathrm{mg} \text {, Ferro } \\
30,0 \mathrm{mg} \text {, Cobre 10,0mg, Manganês } 90,0 \mathrm{mg} \text {, Zinco } 80,0 \mathrm{mg} \text {. }\end{array}$}} \\
\hline $\begin{array}{l}{ }^{2} \text { Fase crescimento:. Vit. A 9.775UI, Vit. D3 2.255UI, Vit. E } \\
25,0 \mathrm{mg} \text {, Vit. K3 } 3,150 \mathrm{mg} \text {, Vit. B1 } 1,725 \mathrm{mg} \text {, Vit. B2 }\end{array}$ & & & \\
\hline
\end{tabular}

O tratamento $\mathrm{C}$ fez-se necessário em razão de possível influência da forma física da ração sobre o consumo da ave (Engberg et al., 2002; Meinerz et al., 2001; López et al., 2007). Essa restrição alimentar foi empregada como metodologia de uniformização do consumo de ração, baseada na média de consumo de um lote de aves das duas linhagens, alojado no dia anterior (120 aves, sendo duas repetições de 30 aves de cada linhagem). A ração peletizada e a peletizada controlada foram, na fase inicial, oferecidas na forma triturada. Todas as aves foram pesadas no início do experimento e na ocasião das trocas de ração aos 21, 41 e 45 dias de idade. As variáveis estudadas foram: ganho de peso, consumo de ração, conversão alimentar e taxa de viabilidade.

Aos 46 dias de idade, foram abatidos 180 frangos, sendo seis de cada boxe (seis de cada repetição), escolhidos aleatoriamente. Antes do abate, os frangos foram submetidos a jejum de ração de 10 horas e, após a identificação individual, foram pesados. Os procedimentos de abate foram os mesmos adotados em um abatedouro industrial. $\mathrm{Na}$ avaliação dos cortes (coxa + sobrecoxa, peito), o rendimento foi 
considerado em relação ao peso da carcaça eviscerada (com pés, cabeça e pescoço). Coração, intestinos, fígado e moela foram avaliados em relação ao peso vivo do frango. Para facilitar a retirada da gordura abdominal, as carcaças permaneceram por duas horas na câmara fria. A percentagem de gordura abdominal foi calculada em relação ao peso da carcaça eviscerada.

Para avaliação do desempenho, o delineamento experimental foi inteiramente ao acaso, em arranjo fatorial $3 \times 2$ (três dietas e duas linhagens), totalizando seis tratamentos com cinco repetições cada um, com 30 aves por parcela experimental. Para a avaliação dos rendimentos de cortes (coxas + sobrecoxas, peito) e coração, intestinos, moela e gordura abdominal, o delineamento foi o mesmo com exceção do número de repetições que foi de 30 , sendo cada ave considerada como uma repetição. Os resultados foram submetidos à análise de variância, e as diferenças entre as médias foram analisadas pelo teste de StudentNewman-Keuls. $\mathrm{Na}$ análise, o peso inicial dos pintos foi considerado como covariável (Sampaio, 2002). O modelo de análise de variância foi: $\mathrm{Y}_{\mathrm{ijk}}=\mu+\mathrm{D}_{\mathrm{j}}+\mathrm{L}_{\mathrm{k}}+(\mathrm{DL})_{\mathrm{jk}}+\mathrm{P}_{\mathrm{i}}+$ $\mathrm{E}_{\mathrm{ijk}}$, em que:

$\mathrm{Y}_{\mathrm{ijkl}}=$ observação do período $\mathrm{i}$, da dieta $\mathrm{j}$, na linhagem $\mathrm{k}$ e da repetição 1 ;

$\mu=$ efeito médio geral;

$\mathrm{Dj}=$ efeito da dieta $\mathrm{j}$, sendo $\mathrm{j}=$ farelada, peletizada e peletizada controlada;

$\mathrm{L}_{\mathrm{k}}=$ efeito da linhagem $\mathrm{k}$, sendo $\mathrm{k}=$ Cobb e Ross;

$(\mathrm{Dk})_{\mathrm{jk}}=$ efeito da interação dieta versus linhagem;

$\mathrm{Pi}=$ efeito da covariável peso inicial; e

$\mathrm{E}_{\mathrm{ijkl}}=$ efeito do erro aleatório atribuído à observação, na dieta $\mathrm{j}$, da linhagem $\mathrm{k}$ e na repetição 1 .

\section{RESULTADOS E DISCUSSÃO}

Os dados de consumo de ração, ganho de peso, conversão alimentar e viabilidade são apresentados na Tab. 2.

As aves alimentadas com ração farelada consumiram mais ração $(\mathrm{P}<0,05)$ que as alimentadas com ração peletizada controlada.
Não se pode considerar este resultado como efeito da forma física, pois o consumo destas foi restrito. O objetivo dessa restrição foi o de igualar os consumos das aves alimentadas com ração farelada e peletizada controlada. Essa diferença ocorreu porque as aves alojadas, um dia antes, para determinar o consumo da ração farelada, consumiram menos ração que as do tratamento farelado do experimento.

O consumo das aves alimentadas com ração peletizada foi maior $(\mathrm{P}<0,05)$ que o das aves alimentadas com ração peletizada controlada, resultado esperado, em razão da menor oferta de ração peletizada controlada.

Os frangos alimentados com ração peletizada (Tab. 2) apresentaram maior consumo $(\mathrm{P}<0,05)$ em relação à ração farelada. Estes resultados podem ser justificados pela preferência das aves pela ração processada principalmente em função de facilidade de apreensão e menor desperdício (Mckinney e Teeter, 2004). Resultados semelhantes foram encontrados por Bertechini et al. (1991a), López e Baião (2002), López et al. (2007).

Não houve efeito de linhagem sobre consumo de ração (Tab. 2) de um aos 45 dias de idade. Resultado semelhante foi observado por Murakami et al. (1995) e Stringhini et al. (2003).

Houve interação $(\mathrm{P}<0,05)$ dieta versus linhagem com relação ao ganho de peso (Tab. 2). Os frangos da linhagem Cobb, quando alimentados com a ração peletizada à vontade, apresentaram maior ganho de peso em relação aos frangos da linhagem Ross e não houve diferença entre linhagens com as demais dietas. Esse resultado pode ser explicado em função do maior aproveitamento da ração peletizada pela linhagem Cobb quando comparado com a linhagem Ross. O maior aproveitamento da ração peletizada pela linhagem Cobb pode ser justificado pela menor exigência de energia para mantença em função de características da linhagem em questão, o que levaria ao maior aproveitamento da energia para fins produtivos. Gonzáles et al. (1998b) encontraram maiores ganhos de peso nas aves da linhagem Ross, alimentadas com ração peletizada quando comparadas com aquelas da linhagem Cobb. 
Tabela 2. Consumo de ração, ganho de peso, conversão alimentar e viabilidade dos frangos de 1 a 45 dias de idade, de acordo com os tratamentos e linhagens

\begin{tabular}{|c|c|c|c|c|}
\hline \multirow{2}{*}{ Ração } & \multicolumn{2}{|c|}{ Linhagens } & \multirow{2}{*}{ Média } & \multirow{2}{*}{ CV $(\%)$} \\
\hline & Cobb & Ross & & \\
\hline \multicolumn{5}{|c|}{ Consumo $(\mathrm{g})$} \\
\hline Farelada & 5228 & 5377 & $5303 \mathrm{~B}$ & \\
\hline Peletizada & 5492 & 5507 & $5500 \mathrm{~A}$ & 1,89 \\
\hline Peletizada controlada & 5120 & 5216 & $5169 \mathrm{C}$ & \\
\hline Média & $5280 \mathrm{a}$ & $5367 a$ & & \\
\hline \multicolumn{5}{|c|}{ Ganho de peso $(\mathrm{g})$} \\
\hline Farelada & $3195 \mathrm{aB}$ & $3247 \mathrm{aB}$ & 3221 & \\
\hline Peletizada & $3408 \mathrm{aA}$ & $3331 \mathrm{bA}$ & 3370 & 1,51 \\
\hline Peletizada controlada & $3249 \mathrm{aB}$ & $3218 \mathrm{aB}$ & 3233 & \\
\hline Média & 3284 & 3265 & & \\
\hline \multicolumn{5}{|c|}{ Conversão alimentar (g:) } \\
\hline Farelada & 1,64 & 1,66 & $1,65 \mathrm{~B}$ & \\
\hline Peletizada & 1,61 & 1,65 & $1,63 \mathrm{~B}$ & 1,55 \\
\hline Peletizada controlada & 1,58 & 1,62 & $1,60 \mathrm{~A}$ & \\
\hline Média & $1,61 \mathrm{a}$ & $1,64 \mathrm{a}$ & & \\
\hline \multicolumn{5}{|c|}{ Viabilidade $(\%)$} \\
\hline Farelada & $96,3 \mathrm{aA}$ & $96,6 \mathrm{aA}$ & 96,5 & \\
\hline Peletizada & $84,7 \mathrm{bB}$ & $97,7 \mathrm{aA}$ & 91,2 & 4,03 \\
\hline Peletizada controlada & $94,9 \mathrm{aA}$ & $93,8 \mathrm{aA}$ & 94,3 & \\
\hline Média & 91,9 & 96,0 & & \\
\hline
\end{tabular}

Apesar de as aves que tiveram seu consumo de ração peletizada restrito apresentarem menor consumo de ração, estas apresentaram ganho de peso semelhante aos frangos que consumiram ração farelada (Tab. 2). Essa resposta pode ser explicada pela melhora na digestibilidade dos nutrientes de rações submetidas à peletização e também em função de um maior aproveitamento dos nutrientes das aves submetidas à restrição alimentar (Lippens et al., 2002; Urdaneta-Rincon e Leeson, 2002). Resultados semelhantes foram encontrados por Meinerz et al. (2001).

Houve efeito da forma física $(\mathrm{P}<0,05)$ sobre a conversão alimentar. Aves alimentadas com ração farelada apresentaram pior conversão alimentar quando comparadas com as alimentadas com ração peletizada controlada. Resultado que pode ser atribuído à maior digestibilidade dos nutrientes em rações processadas, além de possível adaptação fisiológica das aves submetidas à restrição alimentar, que melhoram o aproveitamento dos nutrientes pois há redução das exigências de mantença, ou seja, diminuição na taxa de metabolismo basal (Lippens et al., 2002;
Urdaneta-Rincon; Leeson, 2002). Resultados semelhantes foram observados por Meinerz et al. (2001), que encontraram melhor conversão alimentar para os frangos alimentados com ração peletizada restrita quando comparada com a dos alimentados com ração farelada à vontade.

Aves alimentadas com ração farelada e peletizada à vontade não apresentaram diferenças em relação à conversão alimentar $(\mathrm{P}>0,05)$. Esses resultados são semelhantes aos de Ávila et al. (1995). Entretanto, López et al. (2007) encontraram melhor conversão alimentar em aves alimentadas com rações peletizadas.

Não houve efeito de linhagem sobre a conversão alimentar, o que está de acordo com Murakami et al. (1995) e Stringhini et al. (2003), que trabalharam com as mesmas linhagens desta pesquisa.

Houve interação $(\mathrm{P}<0,05)$ dieta versus linhagem com relação à viabilidade das aves (Tab. 2). $\mathrm{Na}$ linhagem Cobb, as aves que consumiram a ração peletizada à vontade apresentaram menor viabilidade $(\mathrm{P}<0,05)$ quando comparadas com as 
dos demais tratamentos. A viabilidade dos frangos da linhagem Ross não foi influenciada pela forma física da ração $(\mathrm{P}>0,05)$. A maior susceptibilidade dos frangos Cobb aos problemas metabólicos (ascite e morte súbita), principais causas das mortalidades neste experimento, pode estar relacionada às diferenças nas curvas de crescimento das duas linhagens. Aos 21 dias de idade, as aves da linhagem Cobb, independentemente da forma física da ração, já apresentavam maior ganho de peso que as da linhagem Ross (Fig. 1). Esses resultados confirmaram os já relatados por Marcato et al. (2006a), que observaram maior precocidade na taxa de crescimento de frangos da linhagem Cobb quando comparados com os da linhagem Ross. Essa maior precocidade da linhagem Cobb, somada ao grande consumo das rações peletizadas, pode aumentar a necessidade de oxigênio com conseqüente aumento da incidência de doenças metabólicas. Estes resultados foram semelhantes aos observados por Nir et al. (1995) e Leeson et al. (1999). Em relação à linhagem, os resultados foram semelhantes aos encontrados por Gonzáles et al. (1998b). Amornthewaphat et al. (2005), entretanto, observaram maior mortalidade em aves da linhagem Ross que consumiram rações peletizadas em relação às aves que consumiram rações fareladas.

Os resultados de rendimento de cortes e pesos de órgãos digestivos estão apresentados na Tab. 3. Para essas variáveis, não houve interação $(\mathrm{P}<0,05)$ forma física das rações versus linhagem.

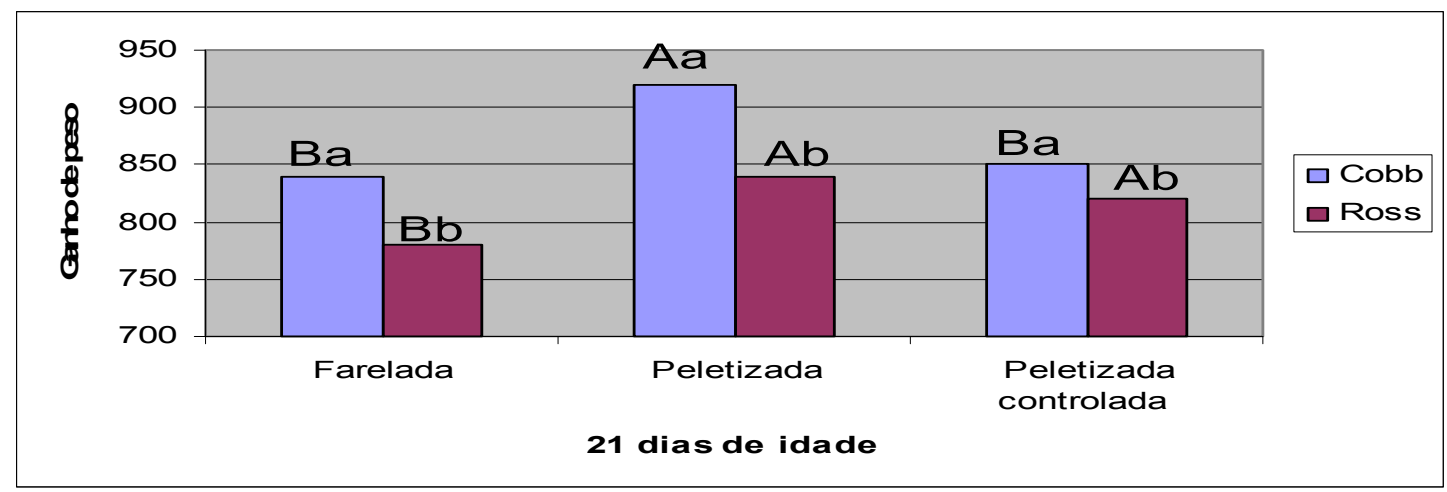

Figura 1. Ganho de peso das aves aos 21 dias de idade de acordo com tratamento e linhagem

Letras distintas, minúsculas para comparar linhagens e maiúsculas para comparar formas físicas diferem entre si pelo teste $\mathrm{SNK}(\mathrm{P}<0,05)$.

Tabela 3. Rendimento de cortes, em relação à carcaça eviscerada, e percentagem de órgãos digestivos, em relação ao peso vivo, de frangos de corte aos 46 dias de idade de acordo com tratamento e linhagem

\begin{tabular}{lcccccc}
\hline & RP $(\%)$ & RCO $(\%)$ & COR $(\%)$ & GA $(\%)$ & MOE (\%) & INT (\%) \\
\hline Dieta & & & & & & \\
\hline Farelada & $35,4 \mathrm{a}$ & $29,0 \mathrm{a}$ & $0,50 \mathrm{a}$ & $1,61 \mathrm{a}$ & $1,33 \mathrm{a}$ & $3,73 \mathrm{~b}$ \\
Peletizada & $35,9 \mathrm{a}$ & $28,8 \mathrm{a}$ & $0,52 \mathrm{a}$ & $1,53 \mathrm{a}$ & $1,13 \mathrm{~b}$ & $3,75 \mathrm{~b}$ \\
Peletizada controlada & $36,0 \mathrm{a}$ & $28,5 \mathrm{a}$ & $0,50 \mathrm{a}$ & $1,52 \mathrm{a}$ & $1,12 \mathrm{~b}$ & $4,10 \mathrm{a}$ \\
\hline Linhagem & & & & & & \\
\hline Cobb & $35,8 \mathrm{a}$ & $28,6 \mathrm{a}$ & $0,51 \mathrm{a}$ & $1,61 \mathrm{a}$ & $1,22 \mathrm{a}$ & $3,80 \mathrm{a}$ \\
Ross & $35,6 \mathrm{a}$ & $28,9 \mathrm{a}$ & $0,51 \mathrm{a}$ & $1,51 \mathrm{a}$ & $1,17 \mathrm{a}$ & $3,91 \mathrm{a}$ \\
\hline CV\% & 4,31 & 5,14 & 12,3 & 28,8 & 13,0 & 12,4 \\
\hline
\end{tabular}

Valores seguidos de letras distintas na coluna diferem entre si pelo teste $\mathrm{SNK}(\mathrm{P}<0,05)$.

$\mathrm{RP}=$ rendimento de peito; $\mathrm{RCO}=$ rendimento de coxas+sobrecoxas; $\mathrm{COR}=$ percentagem de coração; $\mathrm{GA}=$ rendimento de gordura abdominal; $\mathrm{MOE}=$ percentagem de moela; $\mathrm{INT}=$ percentagem de intestinos.

Os rendimentos de peito, de coxas + sobrecoxas, coração e gordura abdominal não foram influenciados pelas dietas $(\mathrm{P}>0,05)$. Resultados semelhantes foram encontrados por Bertechini et al. (1991b), Murakami et al. (1995) e Stringhini et al. (2003). Meinerz et al. (2001) e Leeson et al. 
(1999), entretanto, observaram maior acúmulo de gordura abdominal em aves alimentadas com rações peletizadas em comparação com aves alimentadas com rações fareladas.

Os frangos que receberam rações fareladas apresentaram maior percentagem de moela $(\mathrm{P}<0,05)$ quando comparados com os que receberam ração peletizada, evidenciando $\mathrm{o}$ efeito da forma física sobre essa variável. Isso pode ser devido à menor velocidade de passagem de ração farelada quando comparado com a de ração peletizada, o que provocaria maior estimulação mecânica do trato gastrointestinal e, conseqüentemente, maior atividade dos músculos da moela (Macari et al., 2002). Estes resultados são semelhantes aos relatados por Meinerz et al. (2001) e Huang et al. (2006).

Os frangos alimentados com a ração peletizada controlada apresentaram maior percentagem de intestinos $(\mathrm{P}<0,05)$ do que os alimentados com a ração farelada, mostrando efeito da forma física da ração sobre esta variável. As aves alimentadas com ração peletizada à vontade apresentaram menor percentagem de intestinos que as aves alimentadas com ração peletizada controlada. Essa resposta pode ser conseqüência do menor peso das aves alimentadas com ração peletizada controlada. Frangos alimentados com ração peletizada à vontade apresentaram porcentagens de intestinos semelhantes aos alimentados com ração farelada. De acordo com Meinerz et al. (2001), frangos alimentados com ração peletizada têm maior percentagem de intestino do que aqueles alimentados com ração farelada. As rações peletizadas favorecem o aumento inicial do número de vilosidades duodenais quando comparadas com rações fareladas, aumento que talvez possa não resultar em aumento de peso dos intestinos (Dahlke et al., 2003).

A linhagem não influenciou $(\mathrm{P}>0,05)$ as variáveis avaliadas. Murakami et al. (1995) e Stringhini et al. (2003) não observaram diferenças no rendimento de cortes entre as linhagens avaliadas. Takahashi et al. (2006), no entanto, observaram efeito de linhagem para rendimento de carcaça e cortes. Verifica-se, na literatura, que os efeitos das linhagens sobre os rendimentos de abate não são consistentes, pois nem sempre as comparações são feitas com as mesmas linhagens.
Os resultados deste trabalho evidenciam benefícios da peletização sobre o desempenho de frangos de corte quando comparados com rações fareladas. Esses benefícios podem ser resumidos em maiores ganhos de peso em função do maior consumo, reflexo de melhor palatabilidade e preferência das aves, facilidade de apreensão, que leva à menor movimentação e a menos tempo gasto com alimentação, além de melhor digestibilidade dos nutrientes e, conseqüentemente, melhor aproveitamento da energia.

Com relação à linhagem é importante ressaltar semelhanças em relação às principais variáveis de desempenho (consumo e conversão alimentar) e rendimento de cortes nobres (peito e coxas + sobrecoxas), com exceção do ganho de peso, em que as aves da linhagem Cobb, alimentadas com ração peletizada, obtiveram maiores ganhos; e da viabilidade, em que as aves da linhagem Cobb, também alimentadas com rações peletizadas, apresentaram maior susceptibilidade às doenças metabólicas (ascite e morte súbita).

É importante observar também o efeito do tratamento com ração peletizada controlada sobre a viabilidade da linhagem Cobb, ou seja, uma restrição quantitativa de aproximadamente $6 \%$ no consumo de ração alteraria a curva de crescimento dessa ave por meio da redução no ganho de peso em aproximadamente $4,7 \%$, mas, em compensação, aumentaria a viabilidade em aproximadamente $10 \%$ e melhoraria a conversão alimentar em $2 \%$.

\section{CONCLUSÕES}

O uso de rações peletizadas, independentemente da linhagem, proporciona maior ganho de peso de frangos de corte. A restrição em relação ao consumo de ração peletizada melhora a conversão alimentar e a viabilidade das aves, dependendo da linhagem.

\section{REFERÊNCIAS BIBLIOGRÁFICAS}

AMORNTHEWAPHAT, N.; LERDSUWAN, S. Attamangkune, S. Effect of extrusion of corn and feed form on feed quality and growth performance of poultry in a tropical environment. Poult. Sci., v.84, p.1640-1647, 2005 . 
ÁVILA, V.S.; ROSA, P.S.; GUIDONI, A.L. et al. Desempenho de frangos de corte machos criados no verão até 46 dias de idade, com rações de formas física diferente. In: CONFERÊNCIA APINCO DE CIÊNCIA E TECNOLOGIA AVÍCOLA, 1995, Campinas.. Anais... Campinas: Facta, 1995. p.213-214.

BENETT, C.D.; CLASSEN, H.L.; RIDDELL, C. Feeding broiler chickens wheat and barley diets containing whole, ground and pelleted grain. Poult. Sci., v.81, p.995-1003, 2002.

BERTECHINI, A.G.; ROSTAGNO, H.R.; FONSECA, J.B.; et al. Efeitos da forma física e nível de energia da ração sobre o desempenho e carcaça de frangos de corte. Rev. Bras. Zootec., v.20, p.229-239, 1991a

BERTECHINI, A.G.; ROSTAGNO, H.R.; FONSECA, J.B., et al. Efeitos da temperatura ambiente e nível de energia da ração sobre o desempenho e a carcaça de frangos de corte. Rev. Bras. Zootec., v.20, p.257-265, 1991b

BRIGGS, J.L.; MAIER, D.E.; WATKINS, B.A. et al. Effect of ingredients and processing parameters on pellet quality. Poult. Sci., v.78, p.1464-1471, 1999.

DAHLKE, F.; RIBEIRO, A.M.L.; KESSLER, A.M. et al. Effects of corn particle size and physical form of the diets on the gastrointestinal structures of broiler chickens. Braz. J. Poult. Sci., v.5, p.62-67, 2003.

ENGBERG, R.M.; HEDEMANN, M.S.; JENSEN, B.B. The influence of grinding and pelleting of feed on the microbial composition and activity in the digestive tract of broiler chickens. Br. Poult. Sci., v.43, p.569-579, 2002.

GONZALES, E.; JUNQUEIRA, O.M.; MACARI, M. et al. Uso da restrição alimentar quantitativa para diminuir a mortalidade de frangos de corte machos. Rev. Bras. Zootec., v.27, p.129-136, 1998a

GONZALES, E.; BUYSE, J.; TAKITA, T.S. et al. Metabolic disturbances in male broilers of different strains. 1. Performance, mortality and right ventricular hypertrophy. Poult. Sci., v.7, p.646-1653, 1998b
HAVENSTEIN, G.B.; FERKET, P.R.; QURESHI, M.A. Growth, livability and feed conversion of 1957 versus 2001 broilers when fed representative 1957 and 2001 broiler diets. Poult. Sci., v.82, p.1500-1508, 2003.

HUANG, D.S.; LI, D.F.; XING, J.J. et al. Effects of Feed Particle Size and Feed Form on Survival of Salmonella typhimurium in the Alimentary Tract and Cecal S. Typhimurium Reduction in Growing Broilers. Poult. Sci., v.85, p.831-836, 2006.

JENSEN, L.S.; MERRIL, L.; REDDY, C.V. et al. Observations on eating patterns and rate of food passage of birds fed pelleted and unpelleted diets. Poult. Sci., v.41, p.1414-1419, 1962.

LARA， L.J.C.; BAIÃO, N.C.; AGUILAR, C.A.L. et al. Efeito das fontes lipídicas adicionadas às dietas sobre o desempenho de frangos de corte. Arq. Bras. Vet. Zootec., v.57, p.792-798, 2005.

LEESON, S.; CASTON, L.J.; SUMMERS, J.D. Performance of male broilers to 70 days when fed diets of varying nutrient density as mash or pellets. J. Appl. Poult. Res., v.8, p.452-464, 1999.

LIPPENS, M.; HUYGHEBAERT, G.; DE GROOTE, G. The efficiency of nitrogen retention during compensatory growth of foodrestricted broilers. Br. Poult. Sci., v.43, p.669676, 2002.

LÓPEZ, C.A.A.; BAIÃO, N.C. Efeitos da moagem dos ingredientes e da forma física da ração sobre o desempenho de frangos de corte. Arq. Bras. Med. Vet. Zootec., v.54, p.189-195, 2002.

LÓPEZ, C.A. A.; BAIÃO, N.C.; LARA, L.J.C. et al. Efeitos da forma física da ração sobre a digestibilidade dos nutrientes e desempenho de frangos de corte. Arq. Bras. Med. Vet. Zootec., v.59, p.1006-1013, 2007.

MACARI, M.; FURLAN, R. L.; GONZÁLES, E. (Eds). Fisiologia aplicada a frangos de corte. Jaboticabal: FUNEP/UNESP, 2002. 375p. 
MARCATO, S.M.; SAKOMURA, N.K.; BARBOSA, N.A. Curvas de crescimento e da deposição de nutrientes corporais de duas linhagens de frangos de corte. Rev. Bras. Cienc. Avic., v.8, supl., p.167, 2006 a.

MCKINNEY, L.J.; TEETER, R.G. Predicting effective caloric value of nonnutritive factors: I. Pellet quality and II. Prediction of consequential formulation dead zones. Poult. Sci., v.83, p.1165-1174, 2004.

MEINERZ, C.; RIBEIRO, A.M.L.; PENZ Jr., A.M. et al. Níveis de energia e peletização no desempenho e rendimento de carcaça de frangos de corte com oferta alimentar equalizada. Rev. Bras. Zootec., v.30, p.2026-2032, 2001.

MURAKAMI, A.E.; NERILO, N.; FURLAN, A.C. et al. Desempenho, rendimento de carcaça, cortes e desossa de três linhagens comerciais de frangos de corte. In: CONFERÊNCIA APINCO DE CIÊNCIA E TECNOLOGIA AVÍCOLA, 1995, Campinas.. Anais... Campinas: Facta, 1995. p.279-280.

NIR, I.; HILLEL, R.; PTICHI, I. et al. Effect of particle size on performance. 3. Griding pelleting interactions. Poult. Sci., v.74, p.771-783, 1995.
ROSTAGNO, H.S.; ALBINO, L.F.T.; DONZELE, J.L. et al. Tabelas brasileiras para aves e suínos. Composição de alimentos e exigências nutricionais. Viçosa: UFV, 2005.

SAMPAIO, I.B.M. Estatística aplicada à experimentação animal. 2.ed. Belo Horizonte: FEPMVZ, 2002. 244p.

TAKAHASHI, S.E.; MENDES, A.A.; SALDANHA, E.S.P.B. et al. Efeito do sistema de criação sobre o desempenho e rendimento de carcaça de frangos de corte tipo colonial. Arq. Bras. Med. Vet. Zootec., v.58, p.624-632, 2006.

STRINGHINI, J.H.; LABOISSIÉRE, M.; MURAMATSU, K. et al. Avaliação do desempenho e rendimento de carcaça de quatro linhagens de frangos de corte criadas em Goiás. Rev. Bras. Zootec., v.32, p.183-190, 2003.

URDANETA-RINCON, M.; LEESON, S. Quantitative and qualitative feed restriction on growth characteristics of male broiler chickens. Poult. Sci., v.81, p.679-688, 2002. 